\title{
Is it difficult to provide Evidence on the Improvements on your Patients' Walk after treatment, Physical Therapy and/or Medical Devices?
}

\author{
Danny Rutar* \\ Managing Director, Redback Biotek Limited, Ireland
}

Submission: June 18, 2018; Published: July 30, 2018

*Corresponding author: Danny Rutar, Managing Director, Redback Biotek Limited, Carrowkeel East Inagh, County Clare, Ireland, Email: dannyredback@gmail.com

\section{Opinion}

Italy June 15th, 2018 - BTS Bioengineering is launching the G-WALK in UK, allowing healthcare practitioners to provide evidence on the benefit of their treatment and the use of medical devices. The G-WALK is a breakthrough technology which provides healthcare providers and scientists a simple solution to quickly make an objective, accurate and noninvasive quantitative analysis of varying gait patterns and movement alterations. Thousands of orthopedics, podiatrists and healthcare practitioners around the world have adopted the G-WALK into their daily routine. By doing so they have motivated patients, informed experts and doctors with accurate and useful information, and demonstrated the benefits of treatment to clients with objective, quantifiable data. Now BTS Bioengineering is launching the G-WALK in UK (Figure 1).

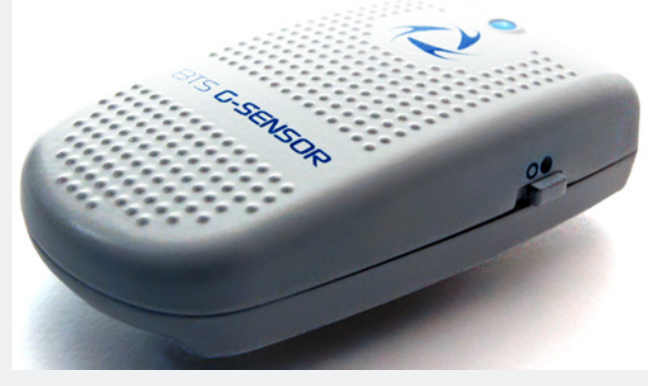

Figure 1: Hardware picture.

Connected to a computer via Bluetooth, the G-WALK system consists of a single miniaturized device of only 37 grams, which holds a special inertial sensor containing 4 accelerometers, 4 gyroscopes and 4 magnetometers, that work combined. As a medical evaluation tool, the G-WALK is built to provide highly accurate and repeatable data. This allows for reliable acquisition of space-time parameters of walking, balance and symmetry, spatial orientation, "beginning" and "end" events in a movement cycle and kinematics of pelvis. The most common clinical tests and protocols are integrated in the G-WALK, such as: i. $\quad$ Six Minutes Walking Test (6MWT) and Timed Up and Go (TUG)

ii. BTS G-WALK and G-WALK+ (Incl. 10 Meter Walk Test) (Figure 2).

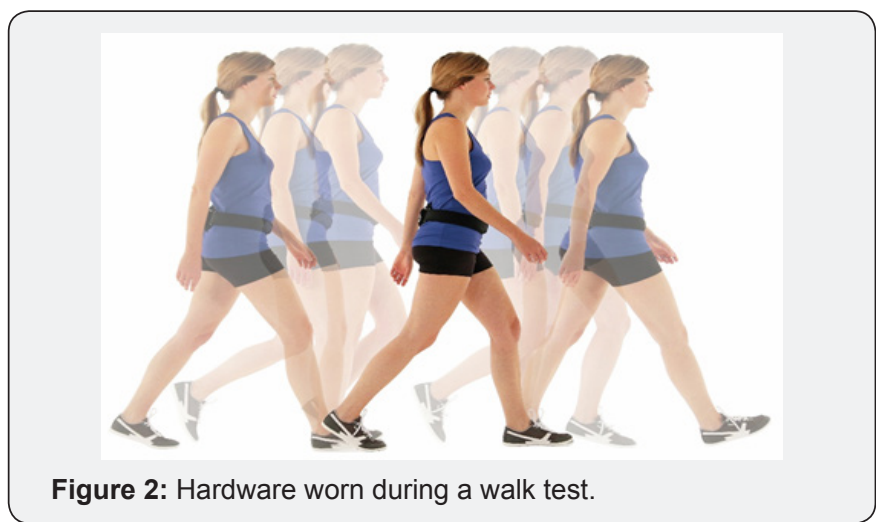

iii. BTS sport protocols (jumping, running and more)

With the comparison tool of the G-WALK, data of different sessions can be compared. As a result, an answer can be given to the important question: What is the benefit of this treatment for my patient compared to another treatment? "BTS Bioengineering has put its 30 years of experience on 3D motion capturing and gait analysis, (Figures $3 \& 4$ ) into this small easy to use, yet highly professional product," said Luca Minesso, CEO of BTS S.p.A.. "We have listened to our customers' needs and developed the G-WALK to be able to quickly obtain objective data on standards clinical test, anytime, anywhere!"

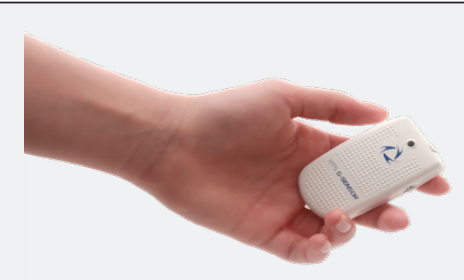

Figure 3: Hardware in a hand. 


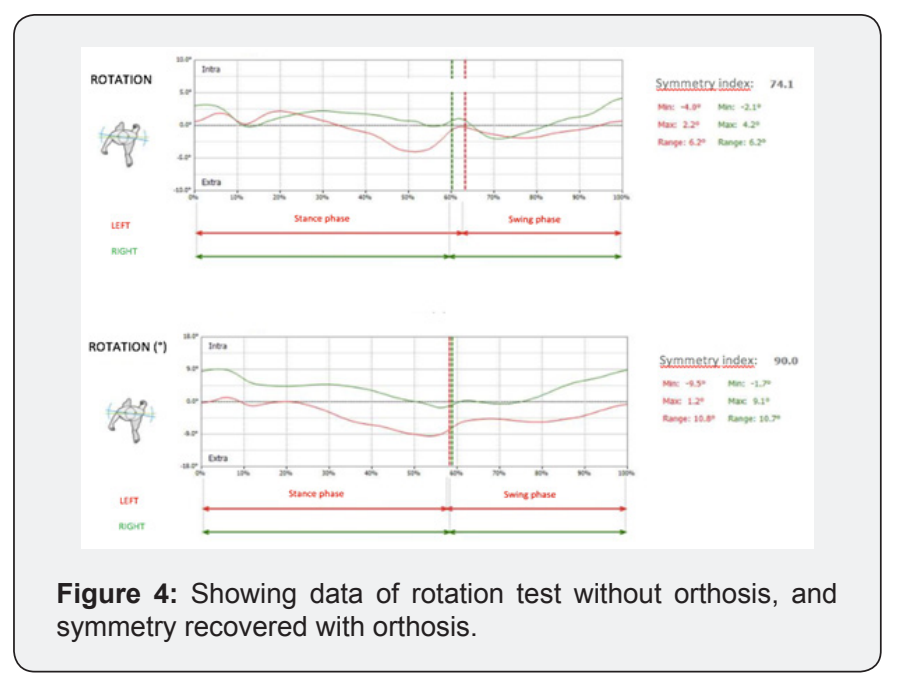

"Launching the new G-WALK in UK is an important step in the development of BTS (Figure 1). We are sure that the clinicians and therapists who will use the G-WALK soon will appreciate the simplicity and the professional protocols in their daily routine," said Marco Carcassoni, Senior Sales Manager Europe for BTS S.p.A..

\section{About BTS Bioengineering}

BTS S.p.A. is an Italian based manufacturer of $100 \%$ digital Medical integrated 3D Motion Capturing Systems and Rehabilitation Aids, who believes that in depth evaluation of motion can truly improve health awareness. Since 1986 BTS has been researching and developing innovative technologies for objective motion analysis, always trying to improve its products and company process. Today BTS has a global research and sales network represented in more than 35 countries, with more than 2.000 installations in leading Clinical and Research Centers all over the World. BTS focuses its product development on providing simple, clear and easy to understand protocols. Please check http://www.btsbioengineering.com/ for more information.

\section{Your next submission with Juniper Publishers will reach you the below assets}

- Quality Editorial service

- Swift Peer Review

- Reprints availability

- E-prints Service

- Manuscript Podcast for convenient understanding

- Global attainment for your research

- Manuscript accessibility in different formats

( Pdf, E-pub, Full Text, Audio)

- Unceasing customer service

Track the below URL for one-step submission https://juniperpublishers.com/online-submission.php 